\title{
Supplementary material of the article Volatile Organic Compound fluxes in a subarctic peatland and lake
}

Roger Seco ${ }^{1,2}$, Thomas Holst ${ }^{1,3}$, Mikkel Sillesen Matzen ${ }^{1}$, Andreas Westergaard-Nielsen ${ }^{2}$, Tao $\mathrm{Li}^{1,2}$, Tihomir Simin ${ }^{1,2}$, Joachim Jansen ${ }^{4,5}$, Patrick Crill ${ }^{4,5}$, Thomas Friborg ${ }^{2}$, Janne Rinne ${ }^{3}$, Riikka Rinnan ${ }^{1,2}$

${ }^{1}$ Terrestrial Ecology Section, Department of Biology, University of Copenhagen, Copenhagen, Denmark

${ }^{2}$ Center for Permafrost (CENPERM), Department of Geosciences and Natural Resource Management, University of Copenhagen, Copenhagen, Denmark

${ }^{3}$ Department of Physical Geography \& Ecosystem Science, Lund University, Lund, Sweden

${ }^{4}$ Department of Geological Sciences, Stockholm University, Stockholm, Sweden

${ }^{5}$ Bolin Centre for Climate Research, Stockholm, Sweden

Correspondence to: Roger Seco (email@rogerseco.cat)

\section{Green Chromatic Coordinate of vegetation at the lakeside eddy-covariance site}

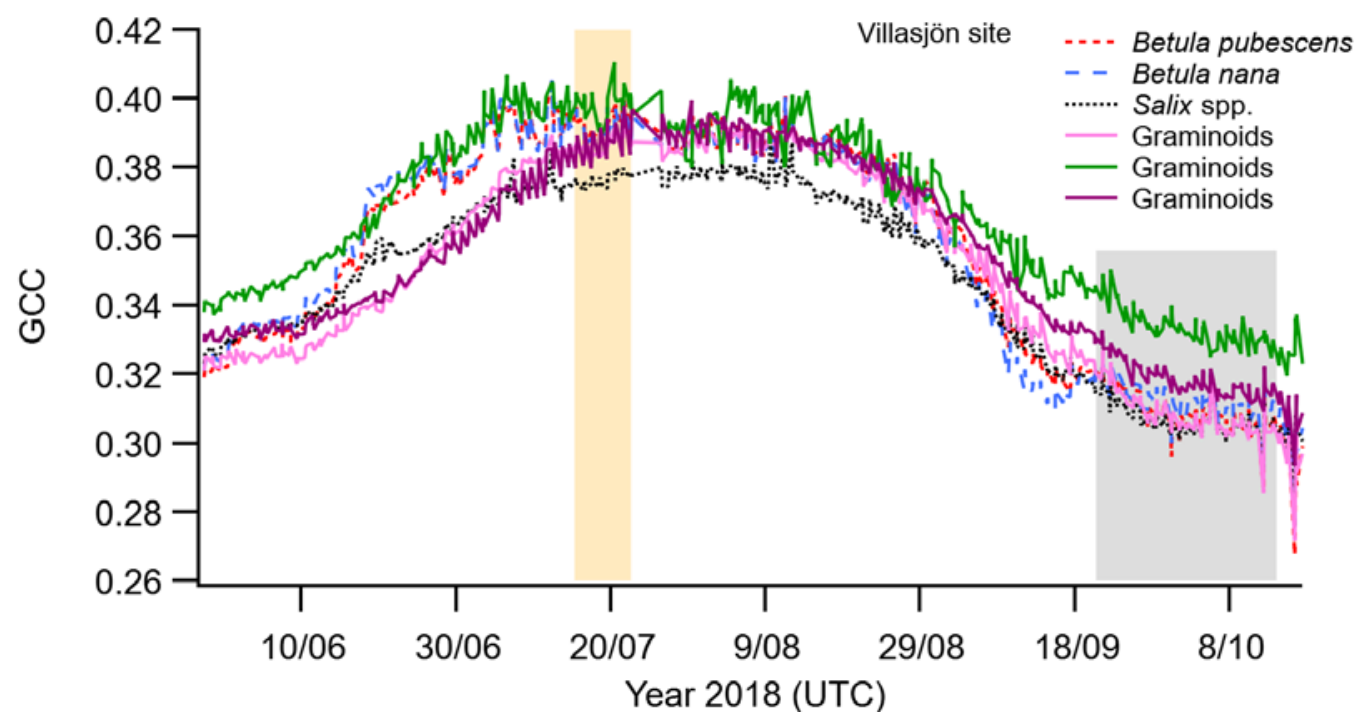

Fig. S1. Green Chromatic Coordinate (GCC) of different vegetation patches located close to the Eddy Covariance tower, dominated by different plant species/groups. The colored backgrounds indicate the periods when PTR-ToF-MS flux measurements were performed. The period in July corresponds to the phenological peak of the growing season, while the period in September/October corresponds to the post growing season. The relatively flat curvature during peak season agrees with observations from low-Arctic heaths and fens at similar latitudes (Westergaard-Nielsen et al., 2013). 


\section{Eddy covariance footprint calculation}

The eddy covariance (EC) footprint was estimated with the model developed by Kljun and colleagues (2015) that takes into account the turbulence characteristics of the atmosphere, the height of the boundary layer, the surface roughness height and the measurement height. The wind turbulence and stability (e.g. friction velocity and Obukhov length) data was calculated from the measurements of the ultrasonic anemometer installed on the EC tower. The height of the boundary layer was obtained from the ERA5 reanalysis results (Copernicus Climate Change Service, 2017). We estimated the surface roughness height of the lake side (ranging from 0.03 to $0.3 \mathrm{~mm}$ ) according to Smith et al. (1988) using the friction velocity since, on open water, wind-induced waves constitute the roughness elements. For the fen side, we calculated surface roughness length $(0.04 \mathrm{~m})$ as one tenth of the estimated canopy height.

\section{Eddy covariance spectral correction}

Even though VOC measurements were performed at $10 \mathrm{~Hz}$, the damping of the turbulence inside the long inlet line and other possible losses of high frequency contributions to the VOC flux required the application of spectral corrections to the calculated fluxes. We chose the empirical method proposed by Aubinet and colleagues (2001), which is based on the comparison of the covariance of the vertical wind speed with a non-attenuated signal (i.e. the temperature measured directly by the sonic anemometer) to that with an attenuated signal (i.e. the VOC; Fig. S2). The resulting transfer function $\left(\delta_{x}\right)$ of our EC system illustrates if the flux information contributed by a particular frequency is measured in its entirety $\left(\delta_{x}=1\right)$, only partially $\left(0<\delta_{x}<1\right)$, or is otherwise completely lost by the high frequency attenuation $\left(\delta_{x}=0\right)$. The experimental data is fitted to a one parameter sigma function

$$
\delta_{x}(f)=\exp \left(-\ln (2) \frac{f^{2}}{f_{0}^{2}}\right)
$$

where $\mathrm{f}$ is the frequency $(\mathrm{Hz})$ and $f_{0}$ is the half-power frequency (i.e. the frequency at which $\left.\delta_{x}=0.5\right)$ that depends only on the system configuration.

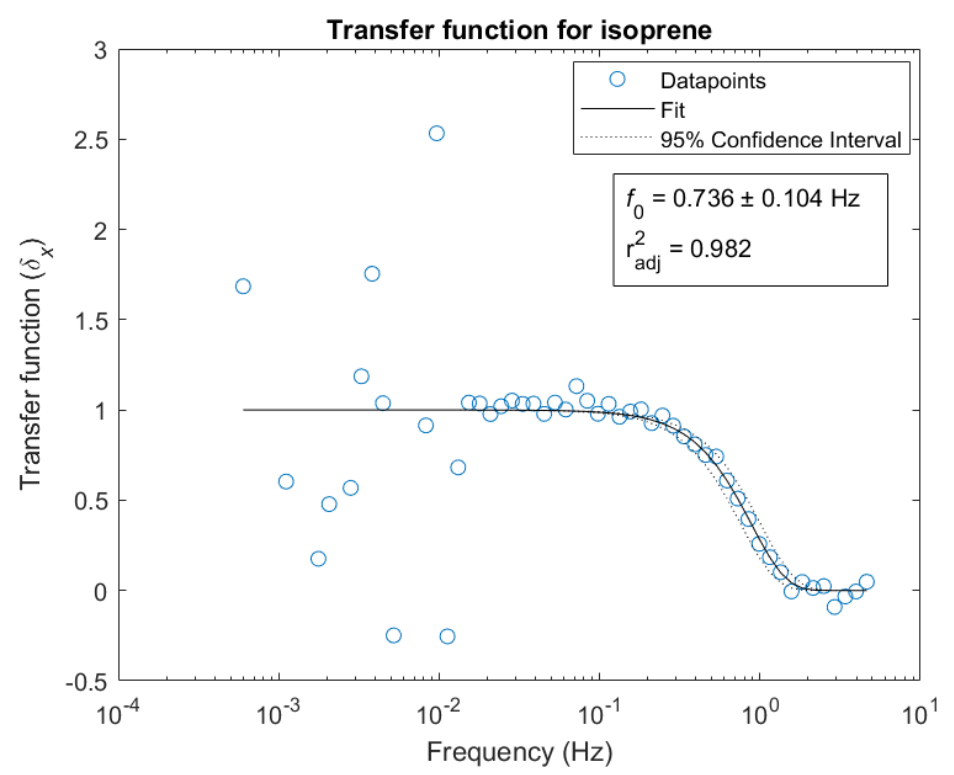

Fig. S2. Transfer function of the VOC eddy covariance system calculated for isoprene. Values calculated experimentally (datapoints) and fit to the one parameter sigma function (solid line) with 95\% confidence interval (dotted lines). 


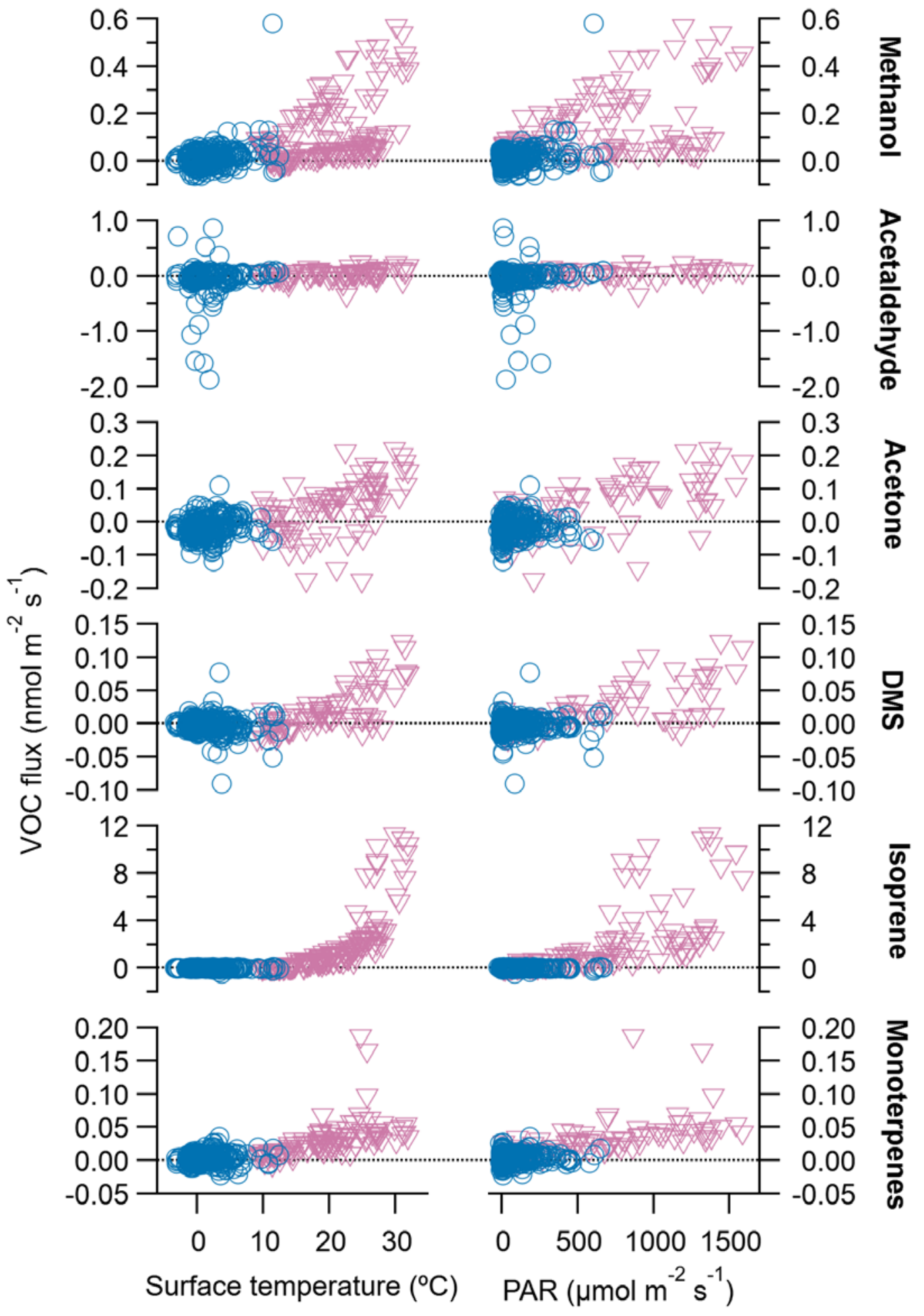

Fig. S3. Fen fluxes of VOCs plotted versus vegetation surface temperature (left panels) and PAR (right panels). Data for July are shown in pink triangles and hat for September in blue circles. 

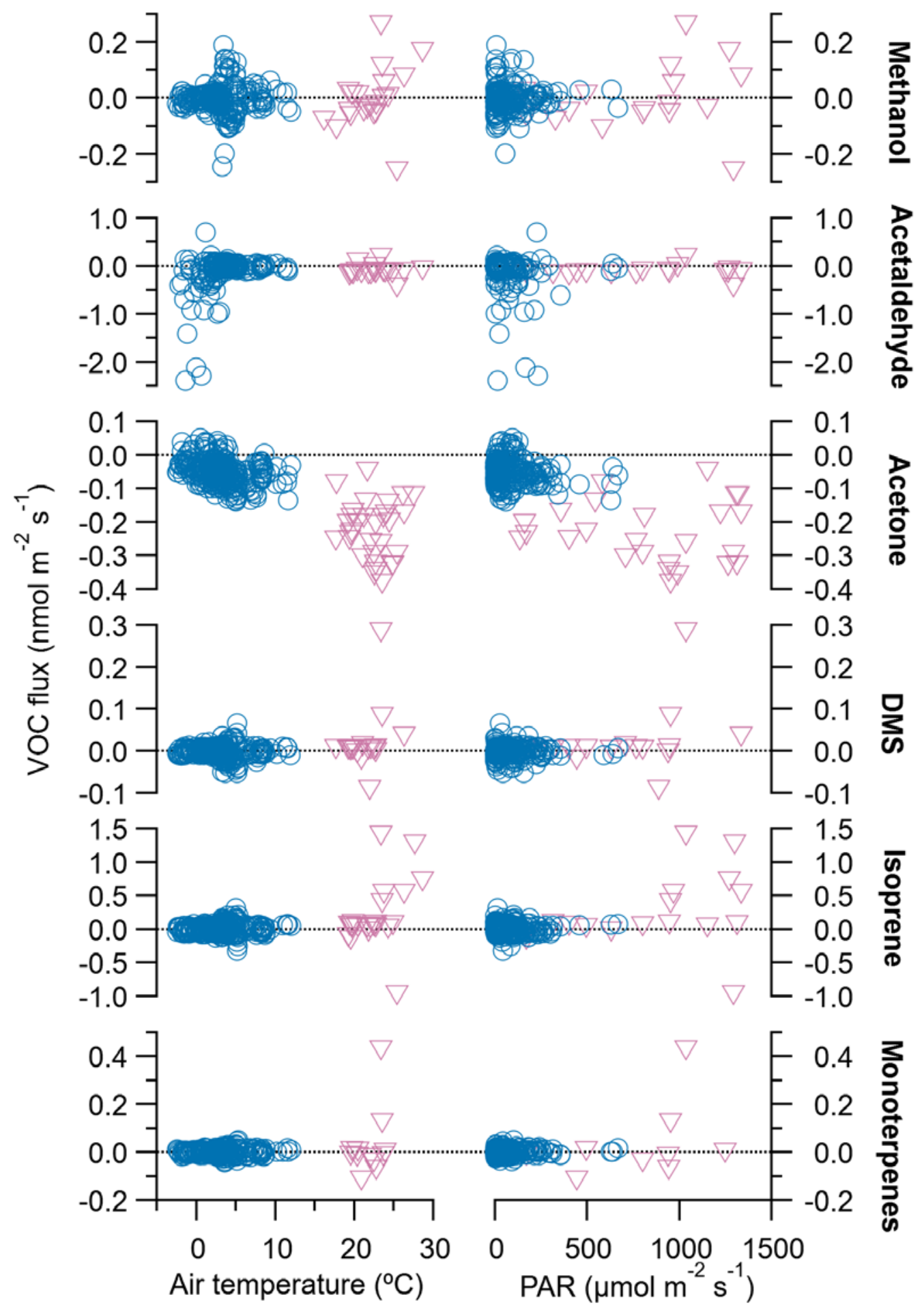

Fig. S4. Lake fluxes of VOCs plotted versus air temperature (left panels) and PAR (right panels). Data for July are shown in pink triangles and hat for September in blue circles. 

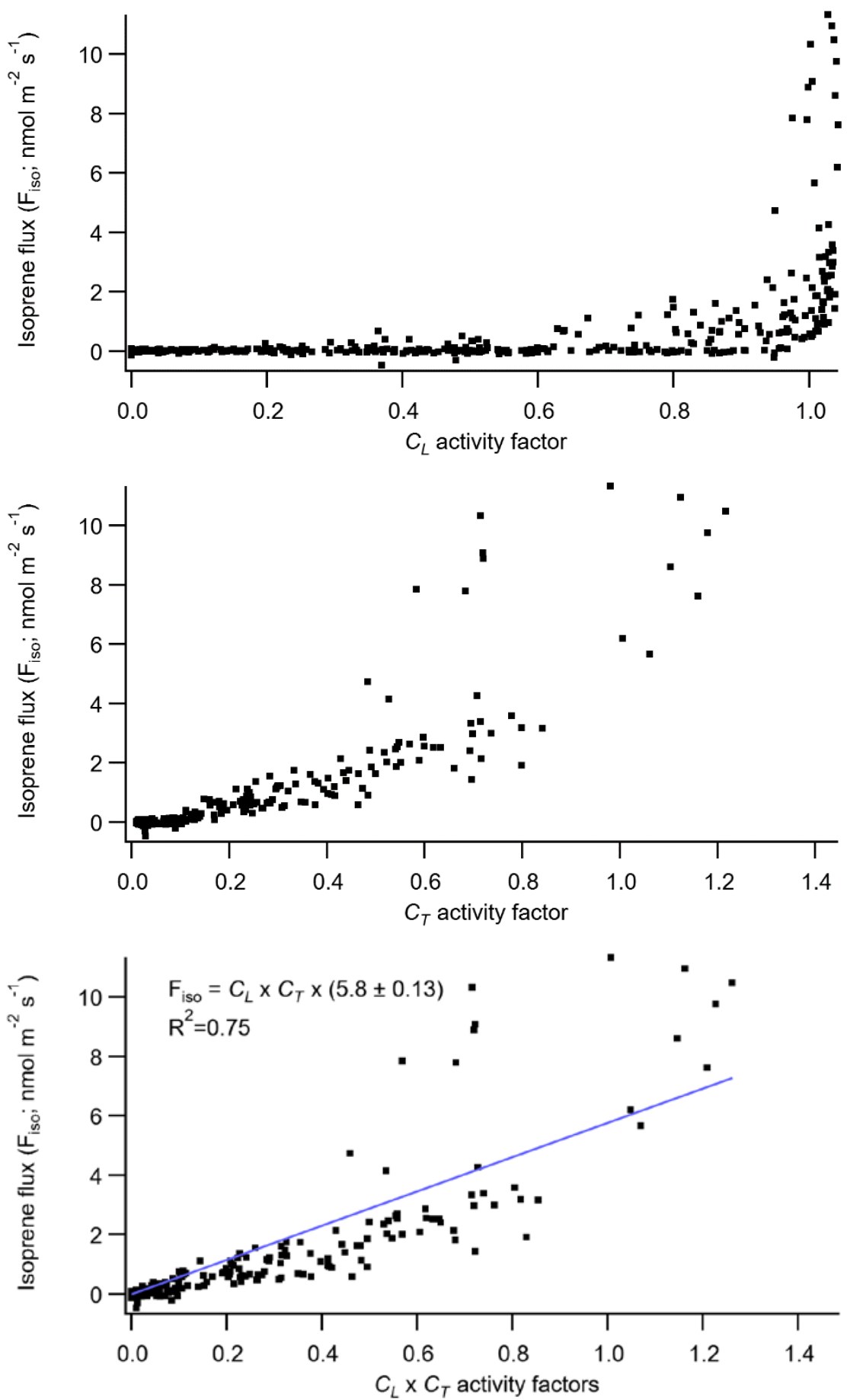

Fig. S5. Isoprene emission fluxes from the fen (for both July and September) plotted against the nondimensional activity factors for light ( $C_{L}$; top panel), temperature ( $C_{T}$; middle panel), and combined light and temperature ( $C_{L} \mathrm{x} C_{T}$; bottom panel), as defined by the G93 model algorithms and its recommended parameters (Guenther et al., 1993). Each data point represents a half-hourly isoprene flux and the corresponding $C_{L}$ and $C_{T}$ factors calculated with the average PAR and surface temperature of that half hour. The line on the bottom panel represents the linear regression of the isoprene fluxes and the combined $C_{L}$ x $C_{T}$ factors, which indicates an isoprene standard (at PAR of $1000 \mu \mathrm{mol} \mathrm{m}{ }^{-2} \mathrm{~s}^{-1}$ and vegetation surface temperature of $30{ }^{\circ} \mathrm{C}$ ) emission rate of $5.8 \pm 0.13 \mathrm{nmol} \mathrm{m}^{-2} \mathrm{~s}^{-1}$. 


\section{REFERENCES}

Aubinet, M., Chermanne, B., Vandenhaute, M., Longdoz, B., Yernaux, M. and Laitat, E.: Long term carbon dioxide exchange above a mixed forest in the Belgian Ardennes, Agric. For. Meteorol., 108(4), 293-315, doi:10.1016/S0168-1923(01)00244-1, 2001.

Copernicus Climate Change Service: ERA5: Fifth generation of ECMWF atmospheric reanalyses of the global climate, Copernicus Clim. Chang. Serv. Clim. Data Store [online] Available from:

https://cds.climate.copernicus.eu/cdsapp\#!/home (Accessed 18 February 2020), 2017.

Guenther, A., Zimmerman, P. R., Harley, P., Monson, R. K. and Fall, R.: Isoprene and Monoterpene Emission Rate Variability - Model Evaluations and Sensitivity Analyses, J. Geophys. Res., 98(D7), 12609-12617, doi:10.1029/93JD00527, 1993.

Kljun, N., Calanca, P., Rotach, M. W. and Schmid, H. P.: A simple two-dimensional parameterisation for Flux Footprint Prediction (FFP), Geosci. Model Dev., 8(11), 3695-3713, doi:10.5194/gmd-8-3695-2015, 2015.

Smith, S. D.: Coefficients for sea surface wind stress, heat flux, and wind profiles as a function of wind speed and temperature, J. Geophys. Res., 93(C12), 15467, doi:10.1029/JC093iC12p15467, 1988.

Westergaard-Nielsen, A., Lund, M., Hansen, B. U. and Tamstorf, M. P.: Camera derived vegetation greenness index as proxy for gross primary production in a low Arctic wetland area, ISPRS J. Photogramm. Remote Sens., 86, 89-99, doi:10.1016/j.isprsjprs.2013.09.006, 2013. 